\title{
A Retrospective Chart Assessment of Clinical Outcomes after Amniotic Suspension Allograft Is Used during Spinal Arthrodesis Procedures
}

\author{
Joseph A. Sclafani ${ }^{*}$, Kevin Liang1, Darcy Mosley², Mark Prevost ${ }^{2}$ \\ ${ }^{1}$ Milestone Research Organization, San Diego, CA, USA \\ ${ }^{2}$ Southern Orthopedics and Sports Medicine Associates, Jasper, AL, USA \\ Email: "jsclafani61@icloud.com
}

Received 16 February 2016; accepted 20 March 2016; published 23 March 2016

Copyright (C) 2016 by authors and Scientific Research Publishing Inc.

This work is licensed under the Creative Commons Attribution International License (CC BY). http://creativecommons.org/licenses/by/4.0/

C. (i) Open Access

\section{Abstract}

Study Design: This retrospective, non-randomized study was designed to evaluate one-year clinical outcomes in a cohort of patients treated with an amniotic suspension allograft as an adjunct to lumbar interbody fusion. Methods: A single-center chart review was conducted to collect preoperative and peri-operative data for patients at or beyond the one year post-operative time point. Results: Patients underwent either anterior $(n=22)$ or posterior $(n=65)$ lumbar interbody fusion. There were six reoperations reported: pseudarthrosis repair $(n=1)$, adjacent level decompression $(n=2)$, removal of symptomatic instrumentation $(n=3)$. Overall VAS score improved from $7.8 \pm 1.7$ to $5.5 \pm 2.4$ at 1 year post-op $(n=86, p=0.0001)$ and overall ODI score improved from 55 \pm 16 to $42 \pm 19$ at 1 year post-op $(n=85, p=0.0001)$. Patients that were 59 years old or older at the time of surgery reported greater improvement in VAS score $(3.6 \pm 2.3$ point improvement, $n=$ 31 ) than patients younger than 59 at the time of surgery $(1.7 \pm 2.2$ point improvement, $n=55, p=$ 0.0005). There was not a significant difference in outcome measures between groups when the data were stratified based on patient BMI, tobacco use, previous surgery, or a primary indication of pseudarthrosis repair. Conclusions: These results indicate that there is a significant clinical improvement when amniotic suspension allograft is used during interbody fusion. Patient groups with increased risk of non-union (increased age, previous pseudarthrosis, and tobacco users) demonstrated improvement in one year post-op outcome measures. Improved clinical outcome implies a high rate of successful arthrodesis in both high and low risk patient populations.

\footnotetext{
"Corresponding author.
} 


\section{Keywords}

\section{Lumbar Fusion, Spine Surgery, Stem Cells, Clinical Outcome}

\section{Introduction}

Iliac crest autograft (ICBG) has long been considered the gold standard to extend locally harvested autograft and supplemental demineralized bone matrix during posterior arthrodesis procedures. Multiple studies have demonstrated a high rate of successful arthrodesis after supplementation with iliac crest autograft secondary to its osteoconductive, osteoinductive and osteogenic properties [1]-[7]. However, patients can experience significant morbidity after posterior iliac crest bone harvesting that can result in a prolonged hospital course and chronic pain at the donor site. Other documented adverse events associated with ICBG harvesting include pelvic fracture, vascular injury, sacroiliac instability, and donor site muscle herniation [8]-[12].

Synthetic and recombinant extenders such as bone morphogenic protein (BMP), a genetically engineered protein with bone growth - stimulating properties, have been approved for use during anterior lumbar spine surgery with an interbody spacer [13]-[15]. Many surgeons now utilize BMP "off-label" as an extender during posterior spinal fusion procedures, both with ICBG or local bone autograft to avoid morbidities associated with ICBG harvesting [16]. Although excellent one and two year rates of solid arthrodesis have been reported after BMP supplementation, recent non-industry funded investigations suggest that there may be an increased risk of malignancy within 24 months of BMP use [17]. The potential for BMP to act through a pro-oncogenic mechanism has necessitated development of alternative extenders that can be used during spinal arthrodesis procedures.

Amniotic suspension allograft (ASA) is an allograft derived from human amnion and cells from the amniotic fluid that can be used to supplement arthrodesis during interbody fusion. The amniotic tissues and fluids contain collagen, proteoglycans, hyaluronic acid, trophic proteins, growth factors and multi-potent cells that stimulate tissue repair and arthrodesis. Donor tissue is recovered and processed using aseptic techniques and rigorous quality standards. Multiple culture, antibody and surface antigen tests are performed for each donor to ensure safety of the tissue. The purpose of this study was to evaluate one year clinical outcome in a cohort of patients treated with an amniotic suspension allograft as an adjunct to lumbar interbody fusion.

\section{Methods}

A retrospective, non-randomized, single-center chart review was conducted for a series of patients that were at least one year post-op from lumbar interbody fusion supplemented by amniotic suspension allograft (NuCel; Nutech Medical, Birmingham, AL, USA). The study was inclusive of patients aged 18 - 90 years that underwent any anterior or posterior interbody fusion technique with ASA supplementation from 2011-2014.

A large sized morselized allograft contains approximately 2 cc's of liquid amniotic suspension for which cell concentration has not been previously reported. Additionally, local autograft was collected, processed through a bone mill and combined with ASA and approximately 30 ccs of cancellous chips for each level fused. This mixture was packed into a PEEK spacer and implanted according to standard surgical techniques.

Following Institutional Review Board approval, pre-operative patient demographics (age, gender, BMI, diagnosis, previous spine surgeries, surgical approach, overall Visual Analog Scale (VAS) for axial low back and leg pain, Oswestry Disability Index (ODI) score, worker's compensation claim status, tobacco use) were collected through the chart review [18] [19]. Operative and peri-operative data including complication rate and length of hospital stay were obtained from available operative reports and hospital discharge summaries by an on-site research coordinator. All data were electronically collected through a sequential series chart review and de-identified prior to analysis by an independent clinical research organization. One year post-operative VAS back and leg pain scores, ODI, and the rate of reoperation were obtained for all patients that received ASA supplementation and had one year follow-up data available. The next temporally available data points, up to 15 months post-op, were used if one year follow-up data was not available. Data were segmented for analysis based on age ( $<59$ years versus $\geq 59$ years), procedure (posterior lumbar interbody fusion versus anterior lumbar interbody fusion), operative level, previous lumbar surgery, tobacco use status, and BMI $(<30$ versus $\geq 30)$. Statistical analyses were performed within each category via two-tailed paired t-tests (example: is there a significant im- 
provement in ODI outcome in patients with BMI > 30). Unpaired t-tests were then used to compare the calculated absolute change in outcome measure per patient to detect significance across parameters (example: is there an absolute greater improvement in ODI outcome per patient with BMI less than 30 compared to those with BMI greater than 30 ?). Data are reported as means \pm SD with significance defined as $p<0.05$.

\section{Results}

Eighty-seven patients (56 female, 31 male) with a mean age of 57 years (range: 26 - 80 years) at the time of surgery were included in the study. A total of 31/87 (36\%) patients had undergone previous lumbar spine surgery. Previous surgeries included decompression only procedures at the level of current revision with ASA $(\mathrm{n}=$ 3), arthrodesis at the level of current revision with ASA (pseudarthrosis repair $(n=8)$, recurrent stenosis $(n=4)$ ), and arthrodesis at the level adjacent to current revision with ASA interbody fusion $(n=16)$. Tobacco use within the post-operative follow up period was reported by $28 / 87$ (32\%) subjects (cigarettes: $n=24$, chewing tobacco: $\mathrm{n}=4)$. The average overall BMI was 31 and $68 / 87(78 \%)$ of patients were affected by a metabolic comorbidity (hypertension, diabetes mellitus, cardiovascular disease). Zero patients were treated under pending litigation or a Worker's Compensation claim (Table 1).

A posterior lumbar interbody fusion with supplemental posterior instrumentation was performed in 65/87 (75\%) patients and 22/87 (25\%) patients underwent a locking anterior lumbar interbody fusion. All patients in this study received a large sized amniotic suspension allograft. There were no reported peri-operative complications or adverse events reported that could be attributed to the amniotic suspension allograft. Median hospital admission time was 3 days (range: 2 - 7 days). There were six reoperations reported within the one year follow up period: pseudarthrosis repair $(n=1)$, adjacent level decompression $(n=2)$, removal of symptomatic instrumentation $(\mathrm{n}=3)$.

Raw preoperative and one year post-operative pain and ODI scores are listed in Table 2 and Table 3. The overall VAS score improved from $7.8 \pm 1.7$ to $5.5 \pm 2.4$ at 1 year post-op ( $\mathrm{n}=86, p=0.0001$ ). Overall ODI score improved from $55 \pm 16$ to $42 \pm 19$ at 1 year post-op $(n=85, p=0.0001)$. Patients that were 59 years old or greater at the time of surgery reported greater absolute improvement in VAS score (3.6 \pm 2.3 point improvement, $\mathrm{n}=31$ ) than patients younger than 59 at the time of surgery ( $1.7 \pm 2.2$ point improvement, $\mathrm{n}=55, p=0.0005)$. There was also a significantly greater improvement in absolute ODI outcome for patients 59 years old or greater at the time of surgery $(16 \pm 15$ point improvement, $\mathrm{n}=32)$ than for subjects less than 59 years old $(11 \pm 12$ point improvement, $\mathrm{n}=53, p=0.05$ ). There was a larger improvement in absolute VAS pain score after a posterior approach to arthrodesis $(2.8 \pm 2.6$ point improvement, $\mathrm{n}=64)$ than was observed after anterior interbody fusion $(1.2 \pm 1.3$ point improvement, $\mathrm{n}=22, p=0.01)$. However, there was not a significant difference in absolute functional outcome as measured by ODI score when patients were stratified based on surgical approach $(p>$ $0.05)$. Similarly, there was significantly less improvement in VAS pain score when the L5-S1 level was included in the fusion construct (L5-S1 included: $1.6 \pm 1.8$ point improvement, $n=45$; L5-S1 not included: $3.1 \pm 2.6, n=$ $41, p=0.002)$ but the level of fusion did not significantly affect absolute functional ODI outcome score ( $p>$ 0.05 ). There was not a significant difference in pain and functional outcome measures between groups when the data was stratified based on patient BMI, tobacco use, previous surgery, or a primary indication of pseudarthrosis repair $(p>0.05)$.

Table 1. Patient demographics.

\begin{tabular}{|c|c|}
\hline & $\mathrm{n}$ \\
\hline Total Patients & 87 \\
\hline Mean Age at Surgery (Years) & 57 \\
\hline Mean BMI & 31 \\
\hline Tobacco Use & 28 \\
\hline \multicolumn{2}{|c|}{ Previous Lumbar Surgery } \\
\hline Decompression Only at ASA Level & 3 \\
\hline Pseudarthrosis at ASA Level & 8 \\
\hline Recurrent Stenosis at ASA Level & 4 \\
\hline Adjacent Level Fusion & 16 \\
\hline
\end{tabular}


Table 2. Raw values of overall VAS pain score, preoperatively and one year post-op.

\begin{tabular}{|c|c|c|c|}
\hline & Pre-op Pain Score & 1 Year Post-op Pain Score & Paired t-Test (p) \\
\hline Overall $(\mathrm{n}=87 / 86)$ & $7.8 \pm 1.7$ & $5.5 \pm 2.4$ & 0.0001 \\
\hline Age $>59(n=32 / 31)$ & $8.2 \pm 1.6$ & $4.6 \pm 2.5$ & 0.001 \\
\hline Age $\leq 59(\mathrm{n}=55 / 55)$ & $7.7 \pm 1.7$ & $6.0 \pm 2.2$ & 0.001 \\
\hline Previous Surgery $(n=32 / 31)$ & $8.4 \pm 1.4$ & $5.6 \pm 2.4$ & 0.001 \\
\hline No Previous Surgery $(n=55 / 55)$ & $7.5 \pm 1.8$ & $5.4 \pm 2.6$ & 0.003 \\
\hline Tobacco Use $(n=29 / 28)$ & $7.9 \pm 1.7$ & $6.1 \pm 2.3$ & 0.002 \\
\hline No Tobacco Use $(n=58 / 58)$ & $7.8 \pm 1.7$ & $5.2 \pm 2.6$ & 0.001 \\
\hline $\mathrm{BMI}>30(\mathrm{n}=41 / 40)$ & $7.5 \pm 1.6$ & $5.2 \pm 2.5$ & 0.0002 \\
\hline $\mathrm{BMI} \leq 30(\mathrm{n}=46 / 46)$ & $8.1 \pm 1.7$ & $5.8 \pm 2.5$ & 0.01 \\
\hline L5-S1 Included in Construct ( $\mathrm{n}=45 / 45)$ & $7.6 \pm 1.7$ & $6.0 \pm 2.2$ & 0.01 \\
\hline L5-S1 not Included in Construct $(n=42 / 41)$ & $8.1 \pm 1.7$ & $5.0 \pm 2.5$ & 0.001 \\
\hline Posterior Approach $(\mathrm{n}=65 / 64)$ & $8.0 \pm 1.7$ & $5.2 \pm 2.4$ & 0.001 \\
\hline Anterior Approach $(n=22 / 22)$ & $7.5 \pm 1.7$ & $6.3 \pm 2.4$ & 0.01 \\
\hline Pseudarthrosis Repair (n = 9/8) & $7.8 \pm 1.5$ & $5.5 \pm 1.8$ & 0.01 \\
\hline
\end{tabular}

Table 3. Raw values of Oswestry Disability Index score, preoperatively and one year post-op.

\begin{tabular}{|c|c|c|c|}
\hline Overall $(\mathrm{n}=87 / 85)$ & $55 \pm 16$ & $42 \pm 19$ & 0.0001 \\
\hline Age $>59(n=32 / 32)$ & $53 \pm 15$ & $36 \pm 20$ & 0.001 \\
\hline Age $\leq 59(\mathrm{n}=55 / 53)$ & $56 \pm 16$ & $45 \pm 18$ & 0.05 \\
\hline Previous Surgery $(n=31 / 31)$ & $60 \pm 17$ & $48 \pm 20$ & 0.05 \\
\hline No Previous Surgery $(n=56 / 54)$ & $52 \pm 14$ & $38 \pm 18$ & 0.001 \\
\hline Tobacco Use ( $n=29 / 29)$ & $57 \pm 16$ & $46 \pm 16$ & 0.05 \\
\hline No Tobacco Use $(n=58 / 56)$ & $54 \pm 16$ & $40 \pm 21$ & 0.001 \\
\hline $\mathrm{BMI}>30(\mathrm{n}=41 / 40)$ & $51 \pm 14$ & $39 \pm 18$ & 0.01 \\
\hline $\mathrm{BMI} \leq 30(\mathrm{n}=46 / 45)$ & $58 \pm 17$ & $45 \pm 20$ & 0.01 \\
\hline L5-S1 Included in Construct $(n=45 / 44)$ & $54 \pm 16$ & $44 \pm 18$ & 0.05 \\
\hline L5-S1 not Included in Construct $(n=42 / 41)$ & $56 \pm 16$ & $40 \pm 21$ & 0.001 \\
\hline Posterior Approach $(n=65 / 63)$ & $55 \pm 15$ & $41 \pm 19$ & 0.0001 \\
\hline Anterior Approach $(\mathrm{n}=22 / 22)$ & $55 \pm 18$ & $44 \pm 21$ & 0.001 \\
\hline Pseudarthrosis Repair $(\mathrm{n}=8 / 8)$ & $56 \pm 13$ & $51 \pm 13$ & $>0.05$ \\
\hline
\end{tabular}

\section{Discussion}

While ICBG remains the "gold standard" for achieving solid arthrodesis, there is significant morbidity associated with harvesting the posterior iliac spine. Other allogeneic lumbar fusion options have been shown to produce reliable fusion rates but have been linked to a wide array of adverse outcomes such as retrograde ejaculation and malignancy [17] [20]. Here, we studied peri-operative and patient based outcomes after lumbar fusion utilizing amniotic suspension allograft as an extender. Our results indicate that there is a significant clinical improvement when ASA is used during both anterior and posterior approaches to lumbar interbody fusion. There 
were zero peri-operative adverse reactions reported that could be attributable to the ASA and the median postoperative hospital admission duration of three days was shorter than previously reported ranges for open approaches to spinal arthrodesis utilizing ICBG [21]-[23].

Overall, there was a significant improvement in both patient reported pain score and functional outcome at the one year post-operative time point. Patient reported improvement in Oswestry Disability and Visual Analog pain indices both exceed the minimum clinical important difference of 12.8 ODI points and 1.2 VAS points, respectively [23]. Several risk factors have been linked to complications and non-union after lumbar arthrodesis including advanced patient age, tobacco use, high patient BMI, metabolic comorbidities, previous non-union, and inclusion of L5-S1 in the fusion construct [24]-[31]. These risk factors did not result in a poor outcome after lumbar spinal fusion utilizing ASA as an extender to local autograft. Patients of more advanced age experienced more improvement in VAS pain score and ODI outcome and there was not a significant difference in VAS pain score or Oswestry Disability Index outcome when groups were stratified by patient BMI, procedures performed for pseudarthrosis repair, or tobacco use. Although patients that underwent fusion that did not include the L5-S1 segment experienced greater improvement in VAS pain score, they did not differ in ODI outcome when compared to subjects that included the L5-S1 segment. Similarly, patients that underwent an anterior lumbar fusion approach experienced greater improvement in VAS pain score but they did not differ in ODI outcome when compared to subjects that underwent a posterior approach.

There are a number of inherent limitations to this study. First, this was a retrospective chart review that did not include radiographic interpretation by a radiologist to evaluate for solid arthrodesis since imaging studies were not collected in a systematic, prospective fashion at the study site. However, it has been widely reported in the literature that lumbar pseudarthrosis causes significant pain and disability secondary to microinstability [28][30]. Although we cannot directly conclude that ASA results in a high rate of solid bony union, it is implied by the significant improvement in patient-reported outcome metrics that a predominance of symptomatic pseudarthrosis would be unlikely within the study group. Second, our study was restricted to a single site and all procedures were performed by a single surgeon. This limits the generalizability of our results to the overall population. However, our study group demographic included a high proportion of patients that would be at risk for developing a non-union, including $78 \%$ of patients with a metabolic comorbidity and $32 \%$ that reported tobacco use during the follow-up period. The significant overall improvement across the entire study population implies that patients without risk factors for non-union will also have similar positive outcomes after ASA is used as an extender for lumbar spinal arthrodesis.

This study demonstrates that the use of ASA during lumbar fusion procedures results in improved one year post-operative pain and functional outcome measures from baseline in a challenging patient population. Improved clinical outcome implies a high rate of successful arthrodesis in both high and low risk patient populations without the perioperative morbidity associated with ICBG harvesting. Future investigation will offer radiographic confirmation of solid arthrodesis and will collect data on long-term postoperative adverse events related to ASA implantation.

\section{References}

[1] Pirris, S.M., Nottmeier, E.W., Kimes, S., O’Brien, M. and Rahmathulla, G. (2014) A Retrospective Study of Iliac Crest Bone Grafting Techniques with Allograft Reconstruction: Do Patients Even Know Which Iliac Crest Was Harvested? Journal of Neurosurgery: Spine, 1-6.

[2] Knox, B.D., Harvell Jr., J.C., Nelson, P.B. and Hanley, E. (1989) Decompression and Luque Rectangle Fusion for Degenerative Spondylolisthesis. Journal of Spinal Disorders, 2, 223-228. http://dx.doi.org/10.1097/00002517-198912000-00002

[3] Kim, S.S., Denis, F., Lonstein, J.E. and Winter, R.B. (1990) Factors Affecting Fusion Rate in Adult Spondylolisthesis. Spine, 15, 979-984. http://dx.doi.org/10.1097/00007632-199009000-00026

[4] Hambly, M.F., Wiltse, L.L., Peek, R.D., DiMartino, P.P. and Darakjian, H.E. (1991) Unilateral Lumbar Fusion. Spine, 16, S295-S297. http://dx.doi.org/10.1097/00007632-199106001-00023

[5] Satomi, K., Hirabayashi, K., Toyama, Y. and Fujimura, Y. (1992) A Clinical Study of Degenerative Spondylolisthesis. Radiographic Analysis and Choice of Treatment. Spine, 17, 1329-1336. http://dx.doi.org/10.1097/00007632-199211000-00012

[6] Frymoyer, J.W. (1994) Degenerative Spondylolisthesis: Diagnosis and Treatment. Journal of the American Academy of Orthopaedic Surgeons, 2, 9-15. 
[7] Herkowitz, H.N. and Sidhu, K.S. (1995) Lumbar Spine Fusion in the Treatment of Degenerative Conditions: Current Indications and Recommendations. Journal of the American Academy of Orthopaedic Surgeons, 3, 123-135.

[8] Arrington, E.D., Smith, W.J., Chambers, H.G., et al. (1996) Complications of Iliac Crest Bone Graft Harvesting. Clin Orthop Relat Res, 329, 300-309. http://dx.doi.org/10.1097/00003086-199608000-00037

[9] Banwart, J.C., Asher, M.A. and Hassanein, R.S. (1995) Iliac Crest Bone Graft Harvest Donor Site Morbidity. A Statistical Evaluation. Spine, 20, 1055-1060. http://dx.doi.org/10.1097/00007632-199505000-00012

[10] Fernyhough, J.C., Schimandle, J.J., Weigel, M.C., Edwards, C.C. and Levine, A. (1976) Chronic Donor Site Pain Complicating Bone Graft Harvesting from the Posterior Iliac Crest for Spinal Fusion. Spine, 17, 1474-1480. http://dx.doi.org/10.1097/00007632-199212000-00006

[11] Summers, B.N. and Eisenstein, S.M. (1989) Donor Site Pain from the Ilium. A Complication of Lumbar Spine Fusion. Journal of Bone and Joint Surgery, 71, 677-680.

[12] Kurz, L.T., Garfin, S.R. and Booth Jr., R.E. (1989) Harvesting Autogenous Iliac Bone Grafts. A Review of Complications and Techniques. Spine, 14, 1324-1331. http://dx.doi.org/10.1097/00007632-198912000-00009

[13] Vaccaro, A.R., Patel, T., Fischgrund, J., Anderson, D.G., Truumees, E., Herkowitz, H., Phillips, F., Hilibrand, A. and Albert, T.J. (2003) A Pilot Safety and Efficacy Study of OP-1 Putty (rhBMP-7) as an Adjunct to Iliac Crest Autograft in Posterolateral Lumbar Fusions. European Spine Journal, 12, 495-500. http://dx.doi.org/10.1007/s00586-003-0561-8

[14] Vaccaro, A.R., Patel, T., Fischgrund, J., Anderson, D.G., Truumees, E., Herkowitz, H., Phillips, F., Hilibrand, A. and Albert, T.J. (2005) A 2-Year Follow-Up Pilot Study Evaluating the Safety and Efficacy of OP-1 Putty (rhbmp-7) as an Adjunct to Iliac Crest Autograft in Posterolateral Lumbar Fusions. European Spine Journal, 14, 623-629. http://dx.doi.org/10.1007/s00586-004-0845-7

[15] Vaccaro, A.R., Patel, T., Fischgrund, J., Anderson, D.G., Truumees, E., Herkowitz, H., Phillips, F., Hilibrand, A., Albert, T.J., Wetzel, T. and McCulloch, J.A. (2004) A Pilot Study Evaluating the Safety and Efficacy of OP-1 Putty (rhBMP-7) as a Replacement for Iliac Crest Autograft in Posterolateral Lumbar Arthrodesis for Degenerative Spondylolisthesis. Spine, 29, 1885-1892. http://dx.doi.org/10.1097/01.brs.0000137062.79201.98

[16] Park, D.K., Kim, S.S., Thakur, N. and Boden, S.D. (2013) Use of Recombinant Human Bone Morphogenic Protein-2 with Local Bone Graft Instead of Iliac Crest Bone Graft in Posterolateral Lumbar Spine Arthrodesis. Spine, 38, E738-E747. http://dx.doi.org/10.1097/BRS.0b013e31828fd23c

[17] Fu, R., Selph, S., McDonagh, M., Peterson, K., Tiwari, A., Chou, R. and Helfand, M. (2013) Effectiveness and Harms of Recombinant Human Bone Morphogenetic Protein-2 in Spine Fusion. A Systematic Review and Meta-Analysis. Annals of Internal Medicine, 158, 890-902. http://dx.doi.org/10.7326/0003-4819-158-12-201306180-00006

[18] Scott, J. and Huskisson, E.C. (1976) Graphic Representation of Pain. Pain, 2, 175-184. http://dx.doi.org/10.1016/0304-3959(76)90113-5

[19] Fairbank, J.C., Couper, J., Davies, J.B. and O’Brien, J.P. (1980) The Oswestry Low Back Pain Disability Questionnaire. Physiotherapy, 66, 271-273.

[20] Singh, K., Ahmadinia, K., Park, D.K., Nandyala, S.V., Marquez-Lara, A., Patel, A.A. and Fineberg, S. (2014) Complications of Spinal Fusion with Utilization of Bone Morphogenetic Protein: A Systematic Review of the Literature. Spine, 39, 91-101. http://dx.doi.org/10.1097/BRS.0000000000000004

[21] Wang, J., Zhou, Y., Zheng, Z., Li, C.Q., Zheng, W.J. and Liu, J. (2010) Comparison of One-Level Minimally Invasive and Open Transforaminal Lumbar Interbody Fusion in Degenerative and Isthmic Spondylolisthesis Grades 1 and 2. European Spine Journal, 19, 1780-1784. http://dx.doi.org/10.1007/s00586-010-1404-z

[22] Schizas, C., Tzinieris, N., Tsiridis, E. and Kosmopoulos, V. (2009) Minimally Invasive versus open Transforaminal Lumbar Interbody Fusion: Evaluating Initial Experience. International Orthopaedics, 33, 1683-1688. http://dx.doi.org/10.1007/s00264-008-0687-8

[23] Copay, A.G., Glassman, S.D., Subach, B.R., Berven, S., Schuler, T.C. and Carreon, L.Y. (2008) Minimum Clinically Important Difference in Lumbar Spine Surgery Patients: A Choice of Methods Using the Oswestry Disability Index, Medical Outcomes Study Questionnaire Short Form 36, and Pain Scales. The Spine Journal, 8, 968-974. http://dx.doi.org/10.1016/j.spinee.2007.11.006

[24] Faciszewski, T., Winter, R.B., Lonstein, J.E., Denis, F. and Johnson, L. (1995) The Surgical and Medical Perioperative Complications of Anterior Spinal Fusion Surgery in the Thoracic and Lumbar Spine in Adults: A Review of 1223 Procedures. Spine, 20, 1592-1599. http://dx.doi.org/10.1097/00007632-199507150-00007

[25] Kucharzyk, D.W. (1999) A Controlled Prospective Outcome Study of Implantable Electrical Stimulation with Spinal Instrumentation in a High-Risk Spinal Fusion Population. Spine, 24, 465-468. http://dx.doi.org/10.1097/00007632-199903010-00012

[26] Schoenfeld, A.J., Carey, P.A., Cleveland III, A.W., Bader, J.O. and Bono, C.M. (2013) Patient Factors, Comorbidities, and Surgical Characteristics That Increase Mortality and Complication Risk after Spinal Arthrodesis: A Prognostic 
Study Based on 5887 Patients. The Spine Journal, 13, 1171-1179. http://dx.doi.org/10.1016/j.spinee.2013.02.071

[27] Edwards II, C.C., Bridwell, K.H., Patel, A., Rinella, A.S., Berra, A. and Lanke, L.G. (2004) Long Adult Deformity Fusions to L5 and the Sacrum: A Matched Cohort Analysis. Spine, 29, 1996-2005. http://dx.doi.org/10.1097/01.brs.0000138272.54896.33

[28] Kim, Y.J., Bridwell, K.H., Lenke, L.G., Rinella, A.S. and Edwards II, C.C. (2005) Pseudarthrosis in Primary Fusions for Adult Idiopathic Scoliosis: Incidence, Risk Factors, and Outcome Analysis. Spine, 30, 468-474. http://dx.doi.org/10.1097/01.brs.0000153392.74639.ea

[29] Kim, Y.J., Bridwell, K.H., Lenke, L.G., Rhim, S. and Cheh, G. (2006) Pseudarthrosis in Long Adult Spinal Deformity Instrumentation and Fusion to the Sacrum: Prevalence and Risk Factor Analysis of 144 Cases. Spine, 31, 2329-2336. http://dx.doi.org/10.1097/01.brs.0000238968.82799.d9

[30] Dickson, D.D., Lenke, L.G., Bridwell, K.H. and Koester, L.A. (2014) Risk Factors for and Assessment of Symptomatic Pseudarthrosis after Lumbar Pedicle Subtraction Osteotomy in Adult Spinal Deformity. Spin, 39, 1190-1195. http://dx.doi.org/10.1097/BRS.0000000000000380

[31] Glassman, S.D., Anagnost, S.C., Parker, A., Burke, D., Johnson, J.R. and Dimar, J.R. (2000) The Effect of Cigarette Smoking and Smoking Cessation on Spinal Fusion. Spine, 25, 2608-2615. http://dx.doi.org/10.1097/00007632-200010150-00011 